\title{
Efeitos da torta da mamona Ricinus communis L. (Malpighiales: Euphorbiaceae) sobre a produção de adubo oriundo da compostagem
}

\author{
João Abílio Diniz'1, Micaely Cristina Reis², Pricila Gomes², Heloiza \\ Oliari Venturine², Chayse Bratz Assunção de Almeida²
}

${ }^{1}$ Instituto Federal de Educação, Ciência e Tecnologia do Tocantins (IFRO). Campus de Ariquemes. Rodovia RO 257, km 13. Sentido Machadinho do Oeste - Zona Rural. Ariquemes-RO. Brasil (CEP 76878-899). E-mail: joão.diniz@ifro.edu.br.

2Instituto Federal de Educação, Ciência e Tecnologia do Tocantins (IFRO). Curso Técnico em Agropecuária. Campus de Ariquemes. Rodovia RO 257, km 13. Sentido Machadinho do Oeste - Zona Rural. Ariquemes-RO. Brasil (CEP 76878-899).

Resumo. Objetivando obter adubo e substrato natural de folhas secas e palhas de gramíneas com e sem enriquecimento nutricional de torta de mamona Ricinus communis L. (Malpighiales: Euphorbiaceae) foi conduzida esta pesquisa no Instituto Federal de Rondônia, Campus Ariquemes, no período de agosto a dezembro de 2016. No experimento realizado em blocos casualizados foram efetuadas quatro repetições de seis diferentes combinações de compostos vegetais. Ao longo do período da pesquisa foram feitas observações de temperaturas e umidades dos compostos pesquisados. No final de 60 e 120 dias, obtiveram-se produções econômicas e sustentáveis de adubo e substrato natural, percebendo-se pelos resultados das análises laboratoriais qualidade superior nos compostos de folhas secas e palhas de gramíneas enriquecidas com a torta de mamona quando comparados com os tratamentos sem este subproduto, indicando sua importância no produto final reciclado e consequentemente no crescimento e desenvolvimento vegetal. Independentemente do material utilizado para compostagem vegetal, a torta de mamona foi determinante na qualidade nutricional melhorando os teores de matéria orgânica e níveis de elementos essenciais às plantas cultivadas. A adição de substrato natural às plantas ornamentais, arbóreas e hortifrutícolas cultivadas no IFRO, Campus Ariquemes, provou a viabilidade do uso desta tecnologia, respaldando sua recomendação em outros ambientes públicos ou privados que disponham de resíduos orgânicos como folhas secas e palhas de gramíneas.

Palavras-chave: Compostagem; Folha seca; Palha de gramínea; Torta de mamona.

Abstract. Effects of castor bean Ricinus communis L. (Malpighiales: Euphorbiaceae) pie on the fertilizer from composting. In order to obtain fertilizer and natural substrate of dry leaves and grass straws with and without nutritional enrichment of castor bean Ricinus communis L. (Malpighiales: Euphorbiaceae) pie, this research was conducted at the Federal Institute of Rondônia,
Recebido:

30/11/2017

Aceito:

24/12/2017

Publicado:

31/12/2017

Acesso aberto Artigo completo

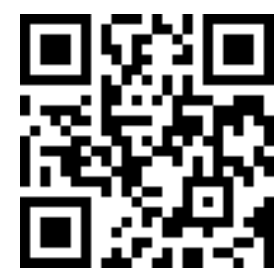

ORCID

(1) 0000-0002-4112-2093 João Abílio Diniz

(1) 0000-0003-3756-0661 Micaely Cristina Reis

D 0000-0001-7944-5827 Pricila Gomes

(D) 0000-0002-4036-3215

Heloiza Oliari

Venturine

D 0000-0003-1767-9657

Chayse Bratz Assunção de Almeida 
Ariquemes Campus, from August to December 2016. In the experiment carried out in blocks were performed four replicates of six different combinations of plant compounds. Throughout the research period, observations of temperatures and humidity of the compounds studied were made. At the end of 60 and 120 days, economic and sustainable yields of fertilizer and natural substrate were obtained, being noticed by the results of the laboratory tests superior quality in the compounds of dry leaves and straws of grasses enriched with the castor cake when compared with the treatments without this byproduct, indicating their importance in the final recycled product and consequently in plant growth and development. Regardless of the material used for vegetable composting, castor bean cake was determinant in nutritional quality, improving the organic matter content and levels of essential elements to the cultivated plants. The addition of natural substrate to the ornamental, arboreal and horticultural crops grown at IFRO Campus Ariquemes has proved the feasibility of using this technology, supporting its recommendation in other public or private environments that have organic residues such as dry leaves and grass straws.

Keywords: Composting; Dry leaf; Grass straw; Castor bean pie.

\section{Introdução}

A disponibilidade de folhas secas e restos de gramíneas em lugares públicos e privados tem sido crescente nos últimos tempos. Se por um lado isto seja bom, haja vista sinalizar presença de plantas ornamentais, arbóreas e hortifrutícolas; por outro, representa preocupações ambientais, pois muitas vezes as destinações de partes destes vegetais ocorrem de forma inadequada, prejudicando a sustentabilidade (Diniz e Pereira, 2015).

Ignorar este fato certamente não constitui ideia aceitável, uma vez que devidamente reciclados estes resíduos orgânicos normalmente geram bons adubos e substratos naturais, podendo ser utilizados de forma econômica e sustentável em benefícios das plantas e do meio ambiente.

É evidente a eficácia da compostagem, seja na produção de adubo ou substrato natural, tendo como origem resíduos de folhas secas e palhas de gramíneas, principalmente quando enriquecidas com tortas obtidas de óleos vegetais ricos em nutrientes essenciais às plantas cultivadas (Nunes, 2009; Leal, 2015; Diniz et al., 2016).

Assim, torna-se oportuno em trabalhos de compostagem vegetal buscar enriquecimento nutricional com tortas de óleos de plantas que possam liberar prontamente elementos essenciais capazes de melhorar, quando aplicados em épocas e quantidades adequadas, o desempenho da vegetação (Bezerra et al., 2009; Fernandes et al., 2009, Oliveira et al., 2010).

Por ser rica em Nitrogênio, a torta de mamona extraída do óleo desta planta pode e deve ser utilizada na compostagem vegetal melhorando sensivelmente seus atributos físicos e químicos com consequentes ganhos na qualidade destes resíduos orgânicos.

A mamoneira (Ricinus communis L.), por ser facilmente encontrada em todas as regiões brasileiras, oferece condições excelentes para que o seu aproveitamento ocorra frequentemente, proporcionando produções de bons adubos e substratos naturais com baixos custos e sustentabilidade garantida.

Para o bem dos recursos naturais esta alternativa ambientalmente e economicamente correta deve ser utilizada com mais intensidade, reaproveitando os diversos resíduos orgânicos em disponibilidade (Ludke et al., 2008; Oliveira et al., 2010; Diniz et al., 2016).

Nesta pesquisa foi avaliada a obtenção de adubos e substratos naturais 
oriundos da compostagem vegetal de folhas secas e palhas de gramíneas enriquecidas ou não com torta de mamona para usos em plantas arbóreas, ornamentais e hortifrutícolas.

\section{Material e métodos}

Num delineamento em blocos casualizados composto por seis tratamentos com quatro repetições, numa área de $24,00 \times 6,00 \mathrm{~m}$, envolvendo 24 parcelas desenvolveu-se o experimento no IFRO, Campus Ariquemes, no período de agosto a dezembro de 2016.

Em cada bloco foram distribuídas seis parcelas experimentais constituídas por formas de madeiras, medindo $1,00 \times 1,00 \times$ $0,10 \mathrm{~m}$, com capacidade de receberem um volume de 100 L de resíduos orgânicos mais $1 \%$ do volume de torta de mamona.

Os tratamentos utilizados foram os seguintes:

\footnotetext{
C1 - composto $100 \%$ de folhas secas, C2 - composto $100 \%$ de palhas de gramíneas,

C3 - composto $100 \%$ folhas secas $+1 \%$ torta de mamona,

C4 - composto $100 \%$ de palhas de gramíneas $+1 \%$ torta de mamona,

C5 - composto $50 \%$ folhas secas $+50 \%$ palhas de gramíneas e

C6 - composto $50 \%$ folhas secas $+50 \%$ palhas de gramíneas $+1 \%$ torta de mamona.
}

Em cada parcela foram colocados os resíduos vegetais padronizando-se $100 \mathrm{~L}$ como referencial das avaliações, conforme sorteios realizados e tratamentos definidos. Nos tratamentos com previsões de uso da torta de mamona adicionou-se de forma homogênea $1 \%$, ou seja, $1 \mathrm{~L}$ deste subproduto obtido do óleo vegetal da mamoneira em cada parcela.

Ao longo do período de observações foram medidas mensalmente as temperaturas dos compostos em decomposições. Aos 60 dias pesou-se o adubo orgânico e aos 120 dias determinouse o teor de umidade, bem como foi feita a pesagem do substrato natural.
As temperaturas foram registradas sempre ao meio dia, utilizando-se geotermômetro colocado por três minutos dentro dos compostos até o atingimento da estabilidade da mesma, enquanto as umidades foram medidas pelo método da estufa a $60^{\circ} \mathrm{C}$.

Os volumes de adubos produzidos foram determinados aos 60 dias de compostagem, utilizando-se medida padrão de $1 \mathrm{~L}$ com auxílio de um tambor plástico de $50 \mathrm{~L}$, redistribuindo e homogeneizando o material de volta ao local que se encontrava depois da operação concluída.

As pesagens dos substratos naturais foram efetuadas em balança de precisão aos 120 dias da experiência, reservando-se amostras para análises laboratoriais e o restante utilizado em plantas arbóreas, ornamentais e hortifrutícolas do IFRO, Campus Ariquemes, observando-se in loco o desempenho com registros fotográficos ao longo de 60 dias.

A análise de variância foi realizada pelo Teste de Tukey a $5 \%$ e $1 \%$ de probabilidade (Pimentel Gomes, 1990).

\section{Resultados e discussão}

Pode-se observar nas Tabelas 1 e 2 variações significativas nas composições das amostras iniciais comparadas com as finais. No geral os teores de matéria orgânica e dos elementos essenciais às plantas cultivadas melhoraram sensivelmente, mostrando a efetividade da compostagem vegetal ao longo dos 120 dias de decomposições dos resíduos orgânicos.

Os melhores tratamentos corresponderam àqueles que além dos resíduos orgânicos tinham na composição torta de mamona. Nesta mesma órbita de conhecimentos científicos, mas em outros trabalhos, pesquisadores estudando enriquecimento de compostos vegetais com torta de mamona também observaram esta tendência (Silva et al., 2012; Oliveira et al., 2010; Leal, 2015).

Os teores de matéria orgânica tiveram incrementos maiores nas combinações com folhas do que nas com gramíneas, podendo-se constatar este fato nas 
comparações dos tratamentos C1 e C3 com C2 e C4, indicando serem aqueles materiais mais ricos em Nitrogênio do que estes.

Apesar dos compostos oriundos de gramíneas terem revelados menores teores de matéria orgânica do que os obtidos da decomposição das folhas, quando adicionados meio a meio (50\% de folhas secas e $50 \%$ de palhas de gramíneas) os resultados da compostagem revelaram-se satisfatórios, conforme pode-se observar na comparação dos tratamentos C5 e C6.

Tabela 1. Composição inicial dos compostos orgânicos.

\begin{tabular}{|c|c|c|c|c|c|c|c|c|c|c|c|}
\hline \multirow[t]{2}{*}{ Tratamento } & \multirow{2}{*}{$\begin{array}{c}\text { pH } \\
\text { Água }\end{array}$} & \multirow{2}{*}{$\begin{array}{c}\text { MO } \\
\text { g.kg }\end{array}$} & \multirow{2}{*}{$\begin{array}{c}P \\
\text { mg.dm }^{-3}\end{array}$} & $\mathbf{K}$ & $\mathrm{Ca}$ & Mg & $\mathbf{H}+\mathbf{A l}$ & Al & CTC & m & $\mathbf{V}$ \\
\hline & & & & \multicolumn{6}{|c|}{$\mathrm{cmol}_{\mathrm{c}} \mathrm{dm}^{-3}$} & \multicolumn{2}{|c|}{$\%$} \\
\hline $\mathrm{C} 1$ & 5,7 & 0,6 & 8 & 0,34 & 0,57 & 0,54 & 0,80 & 0,00 & 2,27 & 0 & 64 \\
\hline $\mathrm{C} 2$ & 6,4 & 2,7 & 16 & 0,51 & 0,35 & 0,58 & 0,80 & 0,00 & 2,27 & 0 & 64 \\
\hline C3 & 6,6 & 0,6 & 7 & 0,45 & 0,47 & 0,42 & 1,00 & 0,00 & 2,33 & 0 & 58 \\
\hline C4 & 6,2 & 2,7 & 18 & 0,79 & 0,51 & 0,88 & 1,00 & 0,00 & 3,17 & 0 & 69 \\
\hline C5 & 6,4 & 1,1 & 11 & 0,51 & 0,57 & 0,57 & 0,70 & 0,00 & 2,31 & 0 & 71 \\
\hline C6 & 6,8 & 5,7 & 21 & 0,97 & 0,88 & 0,71 & 0,80 & 0,00 & 3,39 & 0 & 76 \\
\hline
\end{tabular}

MO = Matéria orgânica; $\mathrm{P}=$ Fósforo; $\mathrm{K}$ = Potássio; $\mathrm{Ca}=$ Cálcio; $\mathrm{Mg}=$ Magnésio; $\mathrm{Al}=$ Alumínio; CTC = capacidade de troca de cátions.

Tabela 2. Composição final dos compostos orgânicos.

\begin{tabular}{|c|c|c|c|c|c|c|c|c|c|c|c|}
\hline \multirow[t]{2}{*}{ Tratamento } & \multirow{2}{*}{$\begin{array}{c}\text { pH } \\
\text { Água }\end{array}$} & \multirow{2}{*}{$\begin{array}{l}\text { MO } \\
\text { g.kg-1 }\end{array}$} & \multirow{2}{*}{$\begin{array}{c}P \\
\text { mg.dm } \\
-3\end{array}$} & $\mathbf{K}$ & $\mathrm{Ca}$ & Mg & $\mathbf{H}+\mathbf{A l}$ & Al & CTC & $\mathbf{m}$ & $\mathbf{V}$ \\
\hline & & & & \multicolumn{6}{|c|}{$\mathrm{cmol}_{\mathrm{c}} \mathrm{dm}^{-3}$} & \multicolumn{2}{|c|}{$\%$} \\
\hline $\mathrm{C} 1$ & 5,2 & 41,2 & 18 & 0,13 & 7,11 & 3,18 & 3,00 & 0,00 & 13,99 & 0 & 78 \\
\hline $\mathrm{C} 2$ & 5,5 & 16,8 & 33 & 0,13 & 2,83 & 3,09 & 2,50 & 0,00 & 8,53 & 0 & 71 \\
\hline C3 & 5,3 & 32 & 35 & 0,13 & 6,10 & 2,51 & 2,80 & 0,00 & 11,54 & 0 & 76 \\
\hline C4 & 5,4 & 27,6 & 40 & 0,13 & 3,6 & 3,82 & 3,00 & 0,00 & 10,52 & 0 & 72 \\
\hline C5 & 5,4 & 34,2 & 31 & 0,16 & 6,18 & 4,81 & 4,50 & 1,02 & 15,60 & 8 & 71 \\
\hline C6 & 5,4 & 21,1 & 40 & 0,13 & 5,06 & 3,26 & 3,00 & 0,00 & 11,42 & 0 & 74 \\
\hline
\end{tabular}

MO = Matéria orgânica; $\mathrm{P}=$ Fósforo; $\mathrm{K}=$ Potássio; $\mathrm{Ca}=$ Cálcio; $\mathrm{Mg}=$ Magnésio; $\mathrm{Al}=$ Alumínio; CTC = capacidade de troca de cátions.

A diminuição do $\mathrm{pH}$ verificada pode ser indicativo do estado de compostagem dos resíduos orgânicos, sendo natural este decréscimo no curto período analisado, devendo com o passar do tempo ser compensado quando aplicado às plantas cultivadas (Cerri, 2008; Valente et al., 2009).

Comportamento semelhante ao do $\mathrm{pH}$ deve ter acontecido em relação aos teores de Potássio que também foram reduzidos quando comparados com os resíduos orgânicos iniciais, sinalizando a necessidade de um maior tempo de compostagem para que níveis deste nutrientes sejam restabelecidos ou, até mesmo, aumentados em comparação aos restos vegetais originais.
Os teores de P, Ca, Mg, H, CTC e os percentuais de saturações de bases seguiram a tendência natural, aumentando com o tempo de compostagem vegetal. Em todas as amostras comparadas estes parâmetros indicadores de qualidade foram superiores nas amostras finais decompostas.

Na Tabela 3 pode-se observar o comportamento da temperatura, umidade e produção de adubo e substrato natural no período de reciclagem. Grande parte destes parâmetros avaliados foram influenciados pelos tratamentos estabelecidos.

As temperaturas foram impactantes no processo de compostagem, principalmente no primeiro mês, revelando nesta fase haver uma tendência da folha seca ser mais quente do que a gramínea, porém do segundo mês em diante não 
foram observadas grandes diferenças de temperaturas entre os tratamentos analisados.

As umidades das amostras foram maiores nos tratamentos $\mathrm{C} 1$ e $\mathrm{C} 5$, ricos em matéria orgânica, provando ser este fator determinante no processo de compostagem, corroborando outras observações científicas neste sentido (Cerri et al., 2008).

Tabela 3. Quadrados médios da análise de variância para temperatura, umidade e produção de adubo e substrato natural no período de reciclagem.

\begin{tabular}{|c|c|c|c|c|c|c|c|}
\hline \multirow[b]{2}{*}{ Fonte de variação } & \multirow[b]{2}{*}{ GL } & \multicolumn{6}{|c|}{ Quadrados médios } \\
\hline & & $\mathrm{T}^{\circ}{ }^{\circ} \mathrm{C}$ & $\mathrm{T} 2^{\circ} \mathrm{C}$ & $\mathrm{T}^{\circ}{ }^{\circ} \mathrm{C} \quad \mathrm{T}^{\circ}{ }^{\circ} \mathrm{C}$ & $\mathrm{U}(\%)$ & Adubo (L) & $\begin{array}{c}\text { Substrato } \\
\text { (kg) }\end{array}$ \\
\hline Bloco & 3 & 0,37 & 10,50 & 0,44 & 0,62 & 47,61 & 2,11 \\
\hline Tratamento & 5 & $1,67^{*}$ & $4,70^{\text {ns }}$ & $0,96^{\text {ns }} \quad 2,06^{*}$ & $6,93^{* *}$ & $21,15^{*}$ & $6,35^{\mathrm{ns}}$ \\
\hline Resíduo & 15 & 0,47 & 2,36 & $1,18 \quad 0,60^{\text {ns }}$ & 1,35 & 7,05 & 2,71 \\
\hline CV (\%) & & 2,53 & 3,89 & 2,85 & 8,32 & 7,41 & 19,61 \\
\hline
\end{tabular}

ns, $* \mathrm{e}^{* *}=$ não significativo e significativo a $5 \%$ e $1 \%$ de probabilidade, pelo Teste de Tukey, respectivamente; $\mathrm{T} 1=$ Temperatura no primeiro mês; $\mathrm{T} 2=$ Temperatura no segundo mês; $\mathrm{T} 3=$ Temperatura no terceiro mês; T4 = Temperatura no quarto mês; U = Umidade.

Nos pátios de órgãos públicos como no caso específico do IFRO, Campus Ariquemes, (Figura 1), bem como em praças, avenidas das cidades e até mesmo em empresas privadas encontram-se normalmente em abundância resíduos orgânicos como folhas secas e palhas de gramíneas, podendo ser recicladas e transformadas em adubos e substratos naturais.
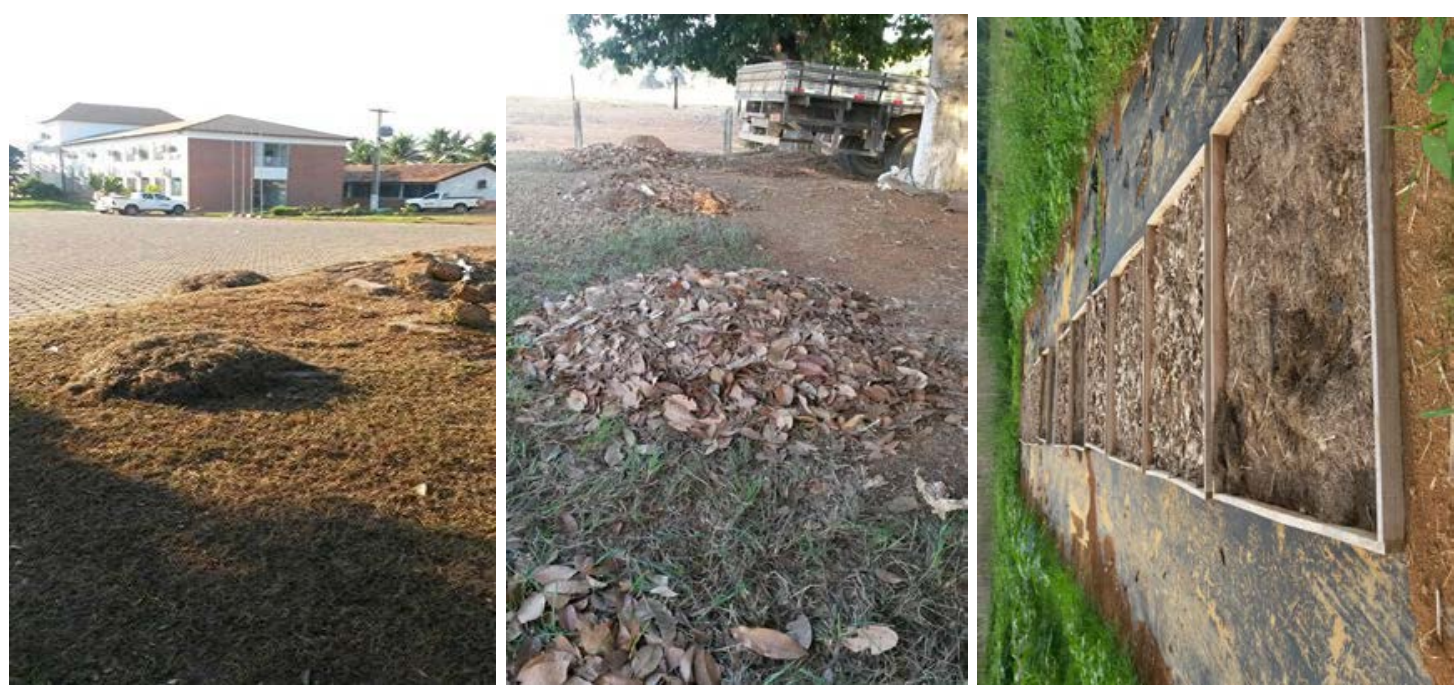

Figura 1. Detalhes da disponibilidade de materiais reaproveitáveis e produção de adubo e substrato natural em ambientes públicos. IFRO Campus Ariquemes, 2016. 
Dos 2.412 L de restos vegetais + torta de mamona colocados em decomposições foram obtidos 857,70 L de adubo orgânico e 200,80 kg de substrato natural. O adubo orgânico não foi utilizado nas plantas cultivadas, deixando-o em decomposição por mais 60 dias até atingir o ponto de substrato natural.

Ficou evidenciada a importância da compostagem vegetal em ambientes públicos como os do IFRO, Campus Ariquemes, motivando a integração e conscientização da comunidade acadêmica, através dos intercâmbios de servidores e alunos, internos e externos.

\section{Conclusão}

A compostagem vegetal pode ser recomendada para ambientes que tenham disponibilidade de resíduos orgânicos como folhas secas e palhas de gramíneas.

A grande vantagem deste processo de reciclagem vegetal reside na praticidade e facilidade de produção de adubo e substrato natural estando esta tecnologia ao alcance de todos.

Em pouco tempo e com baixo custo pode-se produzir adubo e substrato natural, garantindo reaproveitamento de resíduos orgânicos e sustentabilidade.

Várias combinações de compostagens podem ser preparadas com sucesso, principalmente se na mistura utilizar tortas de óleos vegetais ricas em Nitrogênio e outros elementos essenciais às plantas cultivadas como os obtidos das mamoneiras.

Deste trabalho pode-se inferir que o uso da tecnologia de compostagem vegetal pode ser adotada com sucesso, não somente no IFRO, Campus Ariquemes, mas também em outros campi, órgãos públicos e privados, bem como vias e praças administradas por prefeituras municipais.

\section{Agradecimentos}

Agradecemos ao jardineiro terceirizado do IFRO, Campus Ariquemes, senhor Fábio por ter separado e reservado o material vegetal utilizado nesta pesquisa; à Empresa Sobradinho por ter doado a madeira para fabricação das formas de compostagens, bem como ao IFRO/CNPq pelas bolsas de incentivos aos alunos.

\section{Declaração de conflito de interesses}

Os autores declaram não haver conflito de interesses.

\section{Referências}

Bezerra, F. C.; Ferreira, F. V. M.; Silva, T. C. Produção de mudas de berinjela em substratos à base de resíduos orgânicos e irrigadas com água ou solução nutritiva. Horticultura Brasileira, v. 27, n. 2, p. S1348-S1352, 2009. Disponível em: <https://ainfo.cnptia.embrapa.br/digital/ bitstream/CNPAT-2010/11591/1/PA09014. pdf $>$. Acesso em: 16 ago. 2017.

Cerri, C. E. P.; Oliveira, E. C. A.; Sartori, R. H.; Garcez, T. B. Compostagem. Piracicaba: USP, 2008. Disponível em: <https://www.agencia. cnptia.embrapa.br/Repositorio/Compostagem_0 00fhc8nfqz02wyiv80efhb2adn37yaw.pdf>. Acesso em: 16 ago. 2017.

Diniz, J. A.; Pereira, W. E. Índices de sustentabilidade das atividades agrícolas nos biomas Caatinga e Mata Atlântica da Paraíba, Nordeste do Brasil. Revista Brasileira de Gestão Ambiental e Sustentabilidade, v. 2, p. 89-103, 2015. https://doi.org/rbgas.020302

Diniz, J. A.; Santos, E. S.; Iago, R. B. L. Reciclagem vegetal: produção econômica e sustentável de adubo e substrato natural. Anais do XI CONNEPI, Maceió, 2016.

Fernandes, R. C.; Mateus, J. S.; Leal, M. A. A. Utilização de composto orgânico com diferentes níveis de enriquecimento, como substrato para produção de mudas de alface e beterraba. Revista Brasileira de Agroecologia, v. 4, n. 2, p. 113-116, 2009. Disponível em: <http://abaagroecologia.org.br/revistas/index.php/rbagroec ologia/article/view/7845/5613>. Acesso em: 16 ago. 2017.

Inácio, C. T.; Miller, P. R. M. Compostagem: ciência e prática para gestão de resíduos orgânicos. Rio de Janeiro: Embrapa Solos, 2009. 
Fernandes, L. B.; Santos, A. P.; Costa, C. L. L.; Oliveira, F. A.; Goes, G. B. Influência da torta de mamona nas características químicas do solo. Revista Verde de Agroecologia e Desenvolvimento Sustentável, v. 6, n. 3, p. 156-159, 2011. Disponível em: <http://www.gvaa.com.br/revista/index.php/RV ADS/article/download/785/699>. Acesso em: 16 ago. 2017.

Leal, M. A. Produção de fertilizante orgânico $100 \%$ vegetal. EMBRAPA, Agroecologia e Produção Orgânica. 2014. Disponível em: <https://www.embrapa.br/busca-de-noticias//noticia/1865056/artigo-producao-defertilizante-organico-de-origem-100-vegetalpor-meio-da-compostagem>. Acesso em: 16 ago. 2017.

Ludke, I.; Souza, R. B.; Braga, D. O. ; Lima, J. L.; Resende, F. V. Produção de mudas de pimentão em substratos a base de fibra de coco verde para agricultura orgânica. Anais do IX Simpósio Nacional Do Cerrado e II Simpósio Internacional De Savanas Tropicais. Brasília: Embrapa Cerrados, 2008.

Melo, L. C. A.; Silva, C. A.; Dias, B. O. Caracterização da matriz orgânica de resíduos de origens diversificadas. Revista Brasileira de Ciência do Solo, v. 32, n. 1, p. 101-110, 2008. http://dx.doi.org/10.1590/S0100-068320080001 00010

Nunes, M. U. C. Compostagem de resíduos para produção de adubo orgânico na pequena propriedade. Circular Técnica, n. 59, p. 1-7,
2009. Disponível em: <http://www.cpatc. embrapa.br/publicacoes_2010/ct_59.pdf $>$.

Acesso em: 16 ago. 2017.

Oliveira, E. A. G.; Ribeiro, R. L. D.; Guerra, J. G. M.; Carvalho, J. F.; Souza, C. G.; Saiter, O. Enriquecimento nutricional com torta de mamona na formulação de substrato orgânico para produção de mudas de berinjela. Anais do VII ENSub, Goiânia, 2010.

Pimentel Gomes, F. Curso de estatística experimental. 13 ed. São Paulo, Nobel, 1990.

Silva, S. D.; Presotto, R. A.; Marota, H. B.; Zonta, E. Uso de torta de mamona como fertilizante orgânico. Pesquisa Agropecuária Tropical, v. 42, n. 1, p. 19-27, 2012. https://dx.doi.org/10.1590/S1983-40632012 000100003

Valente, B. S.; Xavier, E. G.; Morselli, T. B. G. A.; Jahnke, D. S.; Brum Jr., B. S.; Cabrera, B. R.; Moraes, P. O.; Lopes, D. C. N. Fatores que afetam o desenvolvimento da compostagem de resíduos orgânicos. Archivos de Zootecnia, v. 58, Revisiones, p. 59-85, 2009. Disponível em: <http://www.uco.es/organiza/servicios/ publica/az/php/img/web/07_18_48_1395REVIS IONFatoresValente1.pdf $>$. Acesso em: 16 ago. 2017. 
Informação da Licença: Este é um artigo Open Access distribuído sob os termos da Licença Creative Commons Attribution, que permite uso irrestrito, distribuição e reprodução em qualquer meio, desde que a obra original seja devidamente citada.

Rev. Bras. Gest. Amb. Sustent., 2017, v. 4, n. 8, p. 375-379. 